\title{
Model Application for salinity in Command Area.
}

\author{
Hema R. Parmar ${ }^{1}$, Dr.N.D.Shah ${ }^{2}$,Dr. P.K.Majumdar ${ }^{3}$ \\ ${ }^{1}$ Ph.D student from Charusat University, Changa. E mail-hemavanar@gmail.com \\ ${ }^{2}$ Director of Parul University, Vadodara, Gujarat. \\ ${ }^{3}$ Professor of Civil Engineering , AKS University,Satna, MP, India
}

\begin{abstract}
Unconfined and Perched aquifers in irrigation command are more prone to water logging and salinity problems. Solution to these complexities using mathematical models does play around the source/sink term in majority and suggesting consumptive use as remedial measures becomes more often intentional. Elsewhere many researchers have found the problem caused by topography, clogging of pores and dissolution of nutrients/fertilizers. Numerical modeling of such processes requires adaptive techniques and software application. Such an adaptation is demonstrated in the present paper for the parts of the command area of right bank canal supplying water from Dharoi reservoir built on Sabarmati River in Gujarat state of India. HSI Geo Trans code SWIFT III has been used to generate purpose driven analyses. Results of the modeling analyses encouadoption of such improved technology.

Index Terms: Perched Aquifer, Salinity, SWIFT III model, Unconfined Aquifer.
\end{abstract}

\section{Introduction}

Proceed Salinity often occur at similar positions in the landscape with similar visual symptoms, however they do have different causes, and treatments will therefore be different.. A shallow perched water table in sand over clay soils can also result in water-logging if it seeps out at the surface in down-slope areas. Water logging reduces plant cover and decreases plant tolerance to salinity. Irrigation command areas do exhibit such condition invariably may be in different proportions and many times no body knows whom to blame. Sensitivity of irrigation return flows on stream flow observations were reported in Kendy and Bredehoeft (2006) for Galletin valley in Montana. The hydrologic model of Lower Arkansas River of Colorado by Houk et al. (2006) provided a detailed estimate of the soil salinity levels and water table depths that occur throughout the region. Potential solutions to high soil salinity levels and water-logging problems were investigated on a regional scale using calibratedfinite-difference flow and mass transport modelling for a portion of the Lower Arkansas P.K. Majumdar River Valley in Colorado/USA (Burkhalter and Gates, 2006). Singh et al. (2006), using scale eco-hydrological model SWAP, in combination with field experiments, remote sensing and GIS, showed that reduction of seepage losses halted the rising and declining groundwater levels, and decreased the salinisation in Sirsa district, India. Bastiaanssen et al. (2007) made a strengths-weaknesses-opportunities-threats (SWOT) analysis of soil water flow models and their applications dealing with irrigation and drainage systems. Goncalves et al. (2007) reported modelling studies aimed at assessing water management scenarios at the Huinong irrigation district level using multi-criteria analysis and DSS model. Ahmed and Umar (2009) carried out groundwater flow modelling in a part of central Ganga Plain in Uttar Pradesh. Gusyev and Haitjema (2011) made accurate assessment of water and nutrient balances in large scale wetland systems using conjunctive use modelling of surface water flow in wetlands and groundwater flow in underlying aquifers. Arora and Goyal (2012) applied MODFLOW in the waterlogged area of Indira Gandhi Nahar Pariyojna, Stage I, India. Kaledhonkar et al. (2012) applied prevalent irrigation water quality guidelines for use of sodic groundwater on sandy loam soils for kharif-rabi wheat crop rotation through modeling and found safe SAR guidelines could be easily used for efficient conjunctive water use planning of sodic and fresh water. These are discussed in the present paper. The Dharoi command area (Figure 1) is selected as the study area, exploring the benefit of using readymade regional unconfined and local perched aquifer flow models calibrated and validated in Vanar (2011) and Khediya (2012) respectively. However, the micro level salinity model is developed by extracting the information from Khediya (2012). These models are spatially correlated in Figure 2. Reuse of the earlier developed models provided opportunity to contribute solely the novel issues.

\section{Objectives}

Agriculture is the main non-point polluter of groundwater in irrigated areas as fertilizers and other agrochemicals are the main contaminants in the water that drains out of the root zone to contaminate the aquifer. The concentration of nitrates in the percolated water showed relation with the distributed field water and nitrogen balances over the area. Its concentration in the groundwater depended on the total recharge, pollution loading, groundwater flow and solute transport within the aquifer. Most severe limitation on the practical 
application of models of groundwater contamination problem is the lack of adequate field data. Moreover theoretically, in the salinity modeling of irrigation command, transport mechanism does not merely use the flow vectors but also interact to influence the flow vectors. SWIFT III has such potential with parameters such as Well Index, Salt dissolution and density dependant mass fraction allow simulating such complex phenomena.

Methods of Analysis

\section{Methodology}

For setting out the contour and Graph: Surfer and Grapher software will use.

\section{A. Surfer}

Surfer is a full-featured 3D visualization, contour and surface modelling package that runs on Microsoft Windows. Surfers, the volume measurement readings, terrain modeling, depth modeling, landscape visualization ,surface analysis, contour maps, and 3D surface mapping watersheds are used extensively, contour and 3D surface plots that run on many more. Surfer 9 for Microsoft Windows The program window. Surfer 9 to quickly and easily transform data into outstanding contour maps and surface plots. And with all the options available in Surfer 9, you can do exactly what you customize the map in order to produce the desired presentation. To produce publication quality maps of surfers, quickly and easily, and never more dramatically satisfying.

\section{B Grapher}

Gauge Package graph is the ultimate technology available. This easy to use, powerful and dynamic program will help you create professional quality publication quality graphs in minutes! Wow the audience every time you see one of your graphs. Create 60 or more unique graph types. 2D or 3D linear or logarithmic line, distribution, functions, class balancing, bubble, bar chart, create a floating bar chart graph. Create line, bar, rose, wind, radar polar plot. 2D and 3D vector to generate the plot. To create a line, dispersing, or foam circle diagram. High-low-close or display the candlestick plot professional. Histograms, box-whisker creates statistics and graphs, including pie charts, Q-Q plots.

3. Swift II; Elsewhere SWIFT (Sandia Waste Isolation, Flow and Transport Code) is a fully transient, threedimensional code that solves the coupled equations for transport in geologic media. The equation for governing the fluid flow is written as

Where, $\square \square$ is the fluid density, $\mathrm{u}$ is the magnitude of Darcy

flux vector, $\square \square$ is the porosity, $\mathrm{q}$

rate of fluid withdrawal and $t$ is the time. Further, the

convective-dispersive solution for

contaminant transport is presented as:

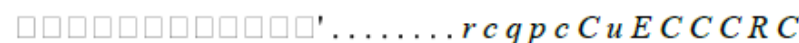

$t$

where $\mathrm{Cr}$ is the concentration of convective components, $\mathrm{Ec}$ is the dispersion tensor, $\mathrm{C}$ is the concentration, $\mathrm{Cq}$ is injected concentration and $\mathrm{Cp}$ is the produced concentration. The salt dissolution mechanism appears in the fluid flow Equation through the source term R C and in the transport, through the source term R'C294. These quantities are defined by

$c c c c R k f C 1 c c c c 295 R C R C$, where Cc is coefficient for increase in fluid - reference temperature reference temperature and pressure and unit concentration and used to characterize the dissolution process, namely, a rate solubility product constant $\mathrm{kC}$ and a mass fraction $\mathrm{fC}$ of soluble to total solid mass. Fluid flow and Dominant-species miscible displacement processes are coupled via fluid density and viscosity. Together they provide the velocity field required in the Dominant species miscible displacement and Trace-species miscible displacement. Mathematical formulations are described in SWIFT (Reeves and Cranwell, 1981) and SWIFT II (Reeves, et al., 1984). Discretization is performed by the finite-difference method using centered weighting in the time and space domains. Matrix solution is performed by two-line successive over relaxation method. A variety of boundary conditions and source terms have been invoked. These include: Prescribed pressure (head) and concentration, prescribed flux of fluid (water) and concentration mass, Well-bore injection/production sub model subject to pumping constraints, Aquifer influence function and free water surface with recharge. General topography is invoked by two terms; SINX is the Sine of the reservoir dip angle along the $\mathrm{x}$-axis and SINY is the Sine of the reservoir dip angle along the y-axis. There is scope for providing undulations in $\mathrm{z}$ direction also in the selected regions. The transmitting capability of the skin is characterized by the well index WI. For specific values of fluid properties: $\mu$ o and $\rho$, the well index may be defined in terms of 
head drop: $0 q$ WI H, Where WIo is measured in $\mathrm{m} 2 / \mathrm{s}$ and is defined by $c 0$ WI $g \mathrm{WI}$ production wells, the well index may be estimated by a one-dimensional, steady-state equatis $k w k$

WI $K z r r$.

Where Ks is the hydraulic conductivity of the skin and where index k ranges over all layers in which the well is completed. This equation is directly applicable for radial coordinates since radius $\mathrm{r} 1$ is defined as the position of the $r X Y$ Schematically, the assumed relation between the skin radius and this average block radius is given by; $w w w w w 328 r r r r r r r$ modeling exercise is mainly concentrated on following aspects: 1 . how waterlogging conditions are related to the parameters related to ground slope, salt dissolution and Well Index, and 2. Can concentrations be improved through salt dissolution and artificial recharge of groundwater.

\section{a. Dharoi command area}

\section{Study Area}

The irrigation command area of the right bank canal of Dharoi reservoir on Sabarmati river in Mehsana district in north Gujarat, India is located in Figure 1. Temperature in the region varies between four degree Celsius in winter to 44 degree Celsius in summer. The humidity during monsoon reaches $95 \%$ or even more. The geographical area of around $9,027 \mathrm{~km} 2$ is rich in agricultural production but is largely dependent on groundwater, both for irrigation and drinking water requirements. Although annual rainfall varies between 500 to $1,500 \mathrm{~mm}$, more than $85 \%$ of it occurs during the months of July and August. Major rivers flowing through the region are Banas, Saraswati, Rupen and Sabarmati. Many of them remain dry in most parts of a year. Sandy to sandy loam type of soil is deposited in the study area. Some areas also indicate clay loam type of soil due to admixture of argillaceous matrix adequately. Both ground water and surface water are being supplied for irrigation in the study area.

\section{b.Geology}

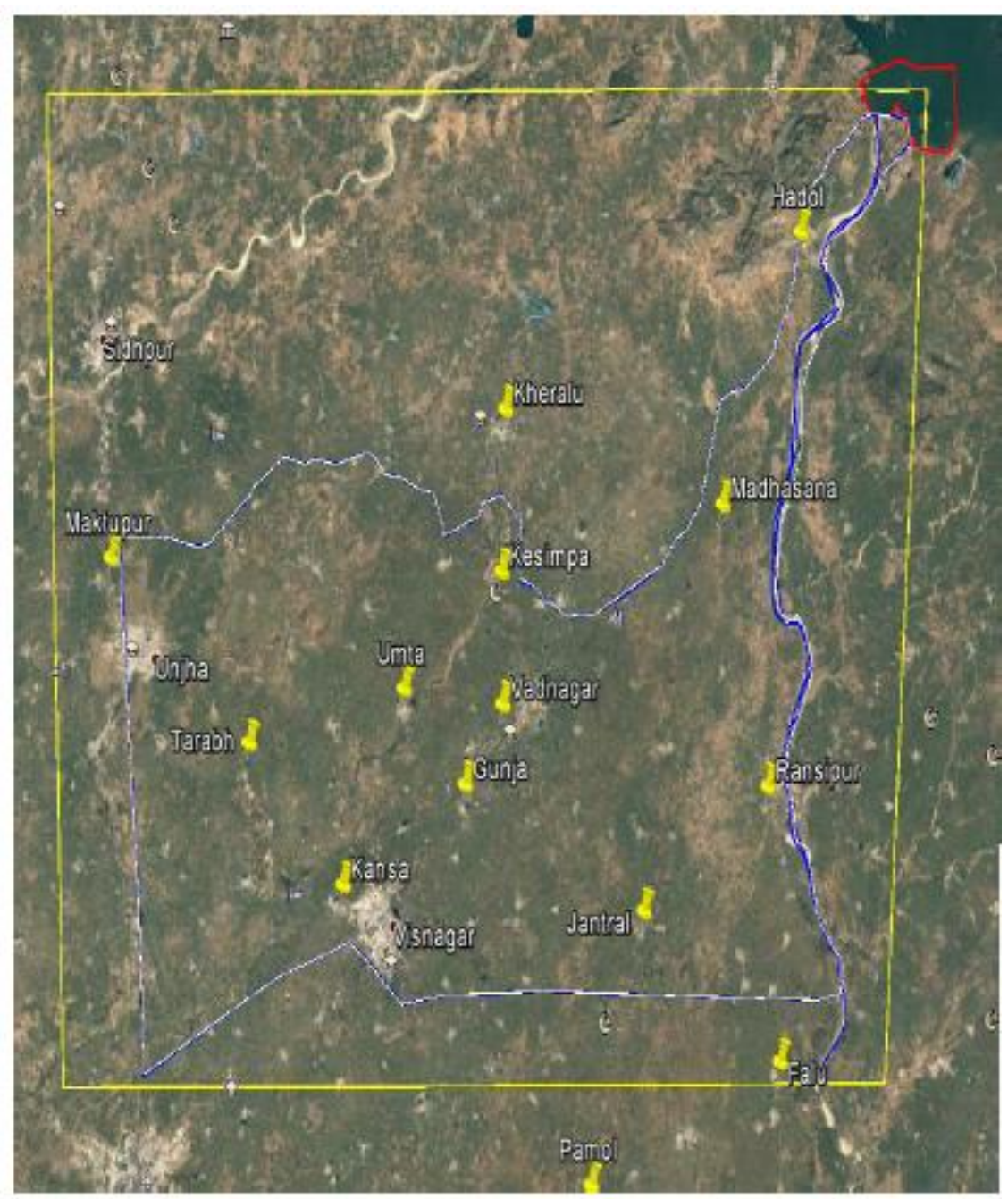

Figure 1. Pearched aquifer area and Study area of modeling 
Thick pile of recent alluvial formation has deposited in the study area. Alternate layers of sand and clay are laid down to a considerable depth of about 180 to $330 \mathrm{~m}$. Blue clay, boulder formation and basement rock is Thick pile of recent alluvial formation has deposited in the study area. Alternate layers of sand and clay are laid down to a considerable depth of about 180 to $330 \mathrm{~m}$. Blue clay, boulder formation and basement rock is also met with at certain places in the study area. The thickness of alluvial formation increases from north-east to south-west. The physical observations indicate coarse sandy material laid down in the Eastern areas where as it becomes finer towards west and south-west areas. Ground water occurs under water table as well as in confined condition in the discontinuous beds of varying thickness of sand, kankar and gravel that constitutes the alluvial aquifers in hard rock terrain. Consolidated formations are mainly dominated by basaltic lava flows associated with inter trappean, infratrappean and archean rock formation represented by phyllites, gneisses, quartzite and granites. Minerals such as Keoline and crude oil are available in the nearby areas. In the adjoining areas of Mehsana and Sabarkantha district the aquifers are highly jointed and fractured or extensively weathered. Wells tapping some thick rock-formations of this type yield as much as 1, 00,000 litres per hour and 40,000 litres per hour are more common. Such aquifer of moderate potential is available within 100-150 m below GL and even as closed as at 30-40 m depth in some of the locations. The phreatic aquifers in the alluvial strata are only suited for shallow wells and low yields tube wells. Bradley and Phadtare (1989) highlighted two distinct aquifer systems, viz. a phreatic aquifer varying in thickness from 9 to $35 \mathrm{~m}$ overlying a series of aquifers and aquitards (Figure 2) and isolated perched aquifers (Figure 4) within the phreatic aquifer. They found that the total thickness of the aquifer system is around $250 \mathrm{~m}$..

Figure 2 Geological alluvial settings in the study area

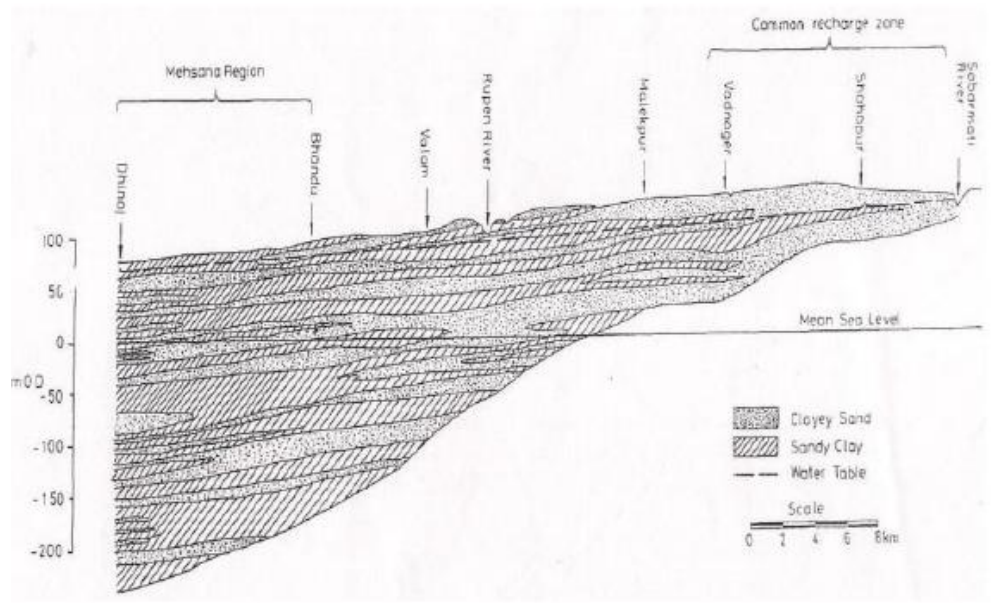

Figure 2 Geological alluvial settings in the study area

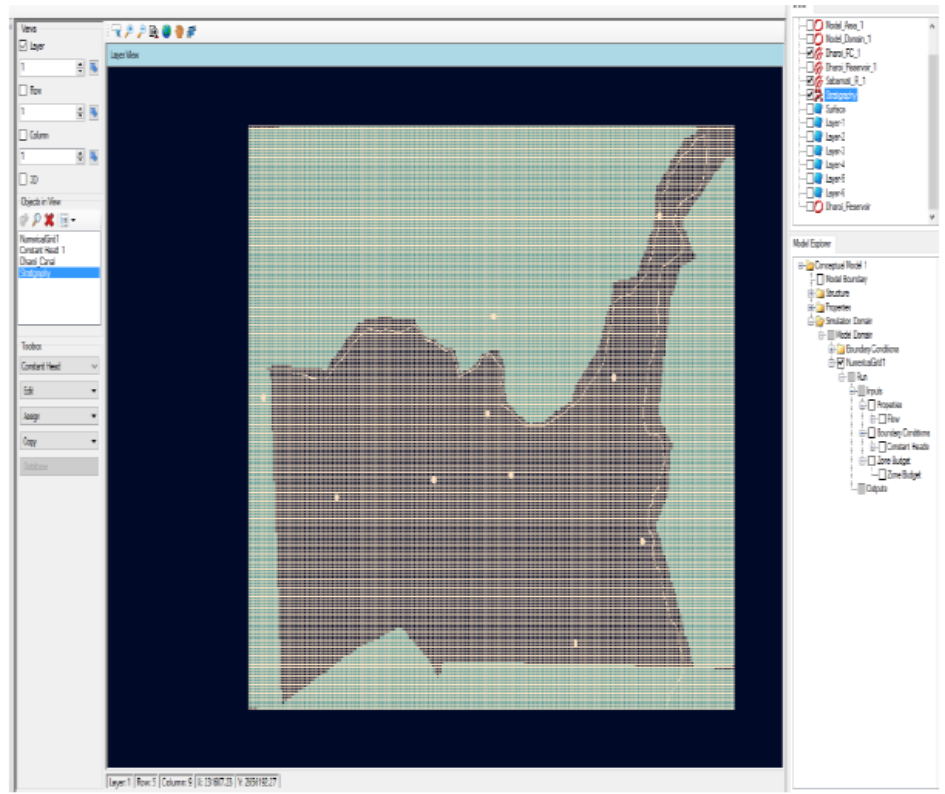

Figure 3 Model Discretization and Boundary Conditions..

Surface water 
The Dharoi dam was commissioned during the year 1985. Flood irrigation is the only adopted method of irrigation by almost all the project beneficiaries. Dharoi project has created a good irrigation facility in the command area, but adverse effects are also noticed. The major problems reported are: the water levels have risen above safe limit, salinity has increased in some areas due to salt leaching, soil fertility has decreased due to admixture of saline water, and net crop production has also decreased due to application of sub standard water and soil deterioration. During the year of good rainfall, most of the command area is facilitated with surface water irrigation. It is said that the canal water is applied without considering actual crop water needs and ample water is being wasted from the canal system. More over the canal lining is distorted and leakage throughout the length of the canals is not ruled out. Some parts of the command area are waterlogged and very shallow water levels .Kharif crops such as Bajri, Jowar, Wheat, Paddy, Fennel, Castor, Groundnut, Sesamum, Rape seed, cotton and Rabi crops like Bajri, Jowar, wheat, cumin, Isabgul, Mustard are generally sown in the area. Presently, cash crops of bajari, cotton and jowar are grown more frequently in the region. Table 1 shows yearly available storages in the reservoir and releases through head regulator of the right bank canal, since 1985-1986. Canal supply is more influenced by the available storage in Dharoi Dam rather than crop water requirements.

\begin{tabular}{|c|c|c|c|c|c|c|}
\hline Year & $\begin{array}{l}\text { Resenvair } \\
\mathbb{W L}(m)\end{array}$ & $\begin{array}{l}\text { Gross } \\
\text { Storage } \\
\text { (Mcunn) }\end{array}$ & $\begin{array}{c}\text { Mater } \\
\text { releasad in } \\
\text { Khyvif } \\
\text { Maum } \\
\end{array}$ & $\begin{array}{c}\text { Water } \\
\text { Roleasod in } \\
\text { Rabi (Mcuw) }\end{array}$ & $\begin{array}{c}\text { Tater } \\
\text { reloased in } \\
\text { hot seather } \\
\text { (Mcuin) }\end{array}$ & $\begin{array}{l}\text { Total water } \\
\text { reloased } \\
\text { (Mcuin) }\end{array}$ \\
\hline $1985-86$ & 184.3676 & 458.779 & 17.55614 & 83.08362 & 31.38803 & 132.0278 \\
\hline $1986-87$ & 180.4785 & 261.8075 & 0 & 0 & 0 & 0 \\
\hline $1987-88$ & 176.239 & 137.0901 & 0 & 0 & 0 & 0 \\
\hline $1988-89$ & 188.1469 & 761.4701 & 0 & 99.36937 & 27.36904 & 126.7384 \\
\hline $1989-90$ & 185.1996 & 516.1639 & 0 & 8480617 & 0 & 84.80617 \\
\hline $1990-91$ & 189.5763 & 907.7052 & 0 & 115.6645 & 74.1889 & 189.8534 \\
\hline $1991-92$ & 189.5611 & 905.0438 & 12.93154 & 149.0604 & 73.72118 & $235.713 !$ \\
\hline $1992-93$ & 189.5763 & 907.7052 & 6.313732 & 165.3835 & 94.37529 & 266.0726 \\
\hline $1993-94$ & 189.2563 & 872.8806 & 29.53015 & 185.1277 & 55.29556 & 269.9534 \\
\hline $1994-95$ & 189.5763 & 907.7052 & 0 & 196.102 & 106.4218 & 302.5238 \\
\hline $1995-96$ & 185.8123 & $1,266.654$ & 24.89621 & 46.35667 & 0 & $71.2528 \mathrm{~s}$ \\
\hline $1996-97$ & 183.7915 & $1,276.818$ & 18.57313 & 0 & 0 & 18.57313 \\
\hline $1997-98$ & 186.6047 & $1,348.902$ & 0 & 116.6333 & 28.3127 & 144.946 \\
\hline $1998-99$ & 183.5873 & $1,348.902$ & 0 & 76.48365 & 0 & 76.48365 \\
\hline 1999-00 & 176.5986 & $1,348.93$ & 0 & 0 & 0 & 0 \\
\hline $2000-01$ & 178.8662 & $1,361.983$ & 0 & 0 & 0 & 0 \\
\hline $2001-02$ & 184.4285 & $1,361.983$ & 12.7274 & $126.546 ?$ & 0 & $139.274 !$ \\
\hline $2002-03$ & 178.3755 & $1,362.011$ & 0 & 0 & 0 & 0 \\
\hline $2003-04$ & 184.9985 & $1,362.039$ & 0 & 193.6034 & 0 & 193.6034 \\
\hline 2004-05 & 178.9973 & $1,362.057$ & 0 & 38.50527 & 0 & 38.50527 \\
\hline $2005-06$ & 189.5763 & $1,362.096$ & 0 & 224.3818 & 0 & 224.3818 \\
\hline $2006-07$ & 189.5763 & $1,362.124$ & 0 & 257.8494 & 65.95161 & 323.801 \\
\hline $2007-08$ & 189.5763 & $1,362.152$ & 0 & 273.8838 & 62.82588 & 336.7097 \\
\hline
\end{tabular}

Source: Gujarat Water Resources Data Center, Gandhinagar, India

\section{C.Groundwater quality problem}

Population of the region face the problems of fluorides and other dissolved salts in drinking water that have shown increasing trend and have exceeded the safe limit since almost two decades now. The process of deterioration of groundwater quality continues unabated and progressively increasing proportion of the population is seen to be affected by fluorosis. Out of total of 1089 villages, 441 are reported to have more than permissible level (> $1.5 \mathrm{ppm})$ of fluoride. Out of 22 lakh total population of Mehsana District, 8.16 lakh (i.e., $39.8 \%$ ) people consume the water with high fluoride concentration. According to the survey carried out by the Department of Health, cases of dental and skeletal fluorosis are reported in 236 villages (Gupta et al., 2005). The deterioration in groundwater quality almost parallels the post 1955 phase, when with the advent of tube wells and electric motors the groundwater extraction went up many folds. Groundwater depletion does not show 
any specific relation with fluoride concentrations in the unconfined aquifer. However some kind of relationship could be seen between fluoride concentration and horse power used for drafting of groundwater in Figure 4. Gradually, the soil fertility was affected with high TDS groundwater and several native crops disappeared. Figure 6 shows the spread of TDS concentration in the study area.

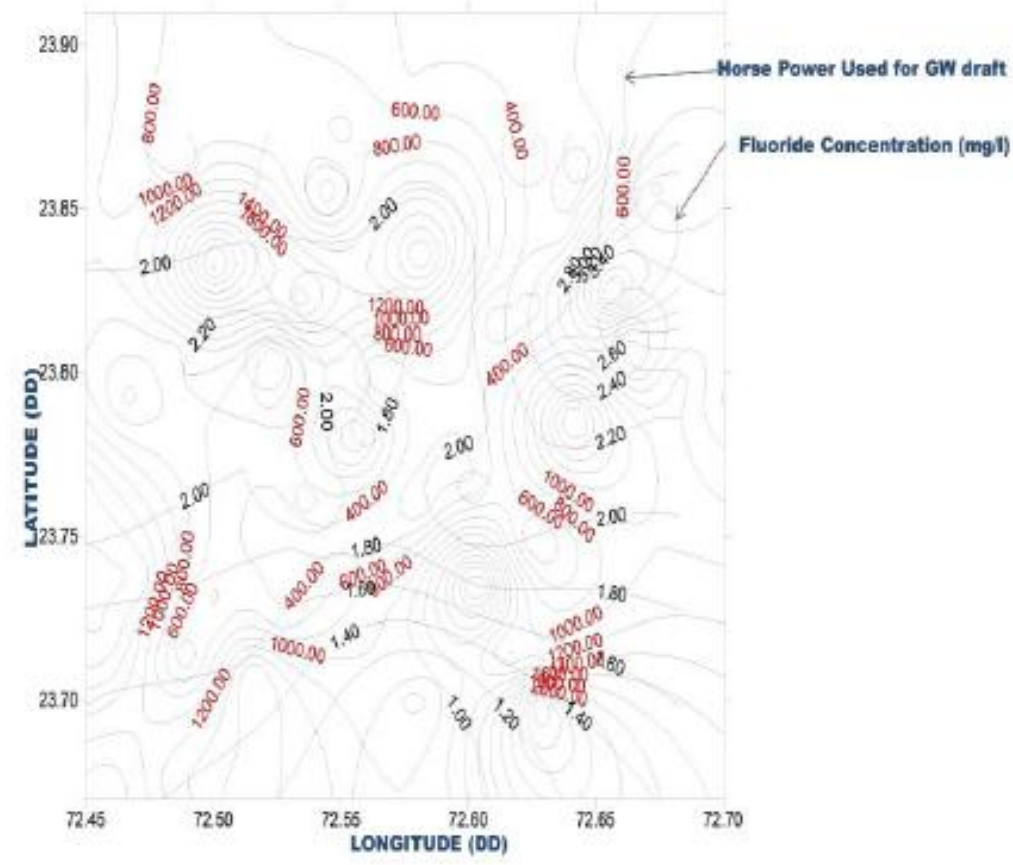

Figure 4 Relation between fluoride concentration in $\mathrm{mg} / \mathrm{l}$ and $\mathrm{hp}$ used for well drafts

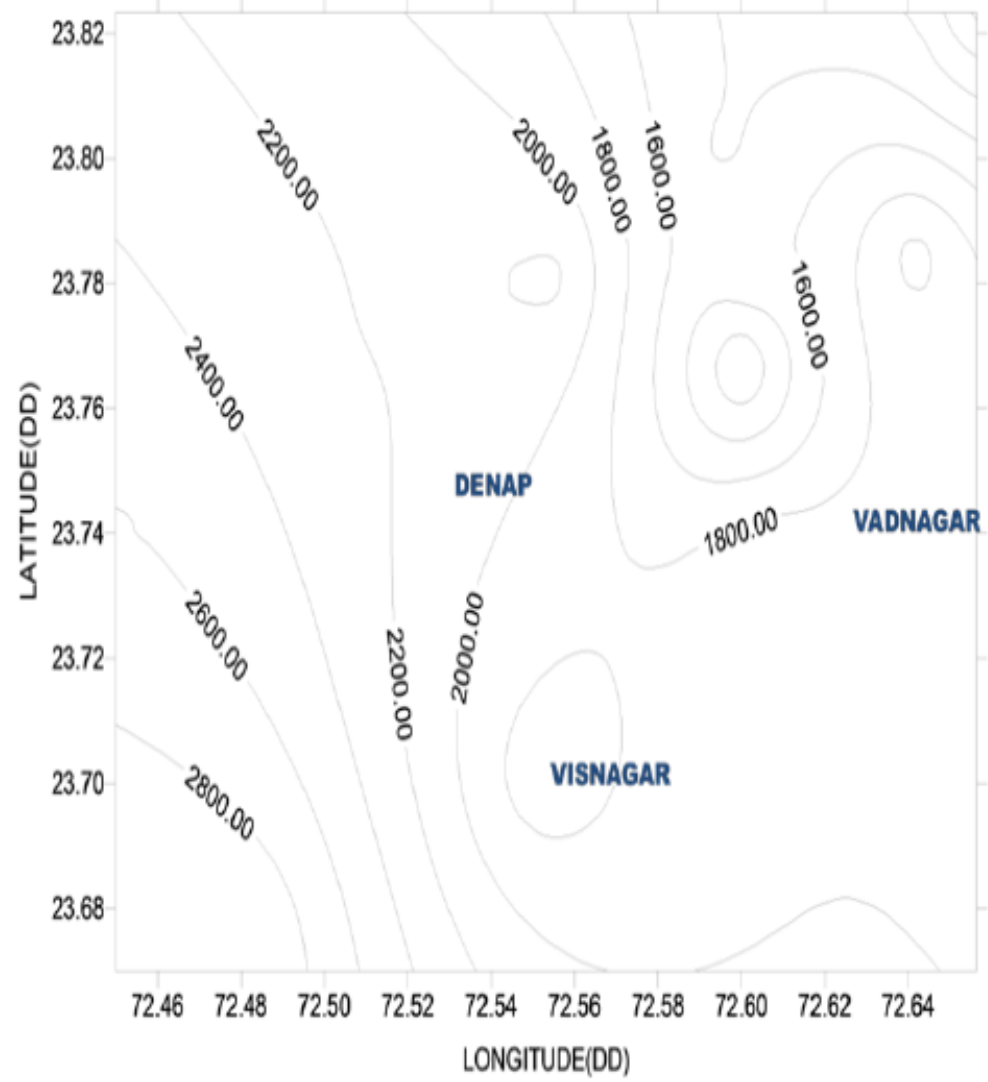

Figure 5 Signature of total dissolved solids in $\mathrm{mg} / \mathrm{l}$ in the perched aquifer (see online version for colours. 
Table 2 Dharoi command soil properties in pre and post irrigation era

\begin{tabular}{|c|c|c|c|c|c|c|}
\hline \multirow[b]{2}{*}{ Seno } & \multirow[b]{2}{*}{ Village } & \multirow[b]{2}{*}{ Taluka } & \multicolumn{2}{|c|}{ Analysis dwring [98] } & \multicolumn{2}{|c|}{ Analysis during 2008} \\
\hline & & & $\begin{array}{c}\text { Total salts in } \\
\text { millimhos }\end{array}$ & $P H$ & $\begin{array}{c}\text { Total salts in } \\
\text { millimhos }\end{array}$ & PH \\
\hline 1 & Malekpur & Vadnagar & 0.066 & 7.30 & 0.460 & 8.20 \\
\hline 2 & Sundhiya & Vadmagar & 0.130 & 8.00 & 0.380 & 7.30 \\
\hline 3 & Denap & Visnagar & 0.050 & 7.90 & 0.380 & 7.30 \\
\hline 4 & Mahemadpur & Visnagar & 0.160 & 7.70 & 0.490 & 7.50 \\
\hline 5 & Khadalpur & Visnagar & 0.180 & 8.10 & 0.280 & 7.50 \\
\hline 6 & Hasanpur & Visnagar & 0.170 & 8.20 & 0.420 & 7.60 \\
\hline
\end{tabular}

Elsewhere HSI GeoTrans code SWIFT solves the following coupled equations for flow and transport in geologic media (Reeves and Cranwell, 1981; Reeves et al., 1984). Equation (3) is written for transient condition, under steady state condition right hand sides of the equation becomes zero.

$-\nabla .(\rho u)-q-q W+R C=\delta(\varphi \rho) \delta t(3)$

where $\nabla .=$ operator, $\rho=$ fluid density, $\varphi=$ porosity, $u=$ Darcy's flux vector, $q=$ rate of

fluid withdrawal, $q w=$ source/sink, $R c=$ salt dissolution. General topography in the model could be invoked by two terms; SINX is the Sine of the reservoir dip angle along the $\mathrm{x}$-axis and SINY is the Sine of the reservoir dip angle along the $\mathrm{y}$-axis. There is scope for providing undulations in $\mathrm{z}$ direction also in the selected regions. Considering a well in each block of the waterlogged region, the transmitting capability of the skin is characterised by the well index WI. The well index may be estimated by a one-dimensional, steady-state equation:

$02 s k \ln (1 w) k$

$W I=\pi K \Sigma \Delta z \operatorname{rr} r(4)$

where $K s$ is the hydraulic conductivity of the skin and where index $k$ ranges over all layers in which the well is completed. For Cartesian coordinates $\Delta X$ and $\Delta Y$, radius $r 1$ is not defined directly, but may be specified in terms of the radius:( ) 1

$r=\Delta X . \Delta Y \pi 2(5)$

Here $r$ is the radius of an equivalent circle and $r 1$ denotes the distance to the average pressure of the cone of influence between $r w$ and $r$. Schematically, the assumed relation between the skin radius and this average block radius is given by:

$\ln (r 1 r w)=r w\{1+(r 1 r w)[\ln (r 1 r w)-1]\} \ln (r-r w)$ (6) Parameter $K s$ can vary spatially as well as temporally, which provides the scope for altering well skin hydraulic conductivity each time step. The calibrated model in Khedia (2012) is operated here to know how water-logging conditions could be related to the parameters such as ground slope and Well Index in perched aquifer scale.

\section{d.Base case model for salinity}

Using SWIFT, the base case model for salinity analyses is developed. The region is much smaller and size of the grid blocks governed by the Peclet number. Single block taken out from the calibrated flow model domain of Khediya (2012) is celled with 20 grids in both $\mathrm{X}$ and $\mathrm{Y}$ directions, resulting in to single block dimensions of $125 \mathrm{~m}$ in each. Vertical heterogeneity is kept similar to that of the flow model, whereas individual layers are kept horizontally homogeneous having properties of the chosen flow model block. Based upon the Peclet number and standard ratio between longitudinal and transverse dispersivities, same are considered as 125 $\mathrm{m}$ and $12.5 \mathrm{~m}$ respectively with diffusivity

\section{e.Altered understanding for salinity}

Prevailing concept of salinity roll around the flow vectors, even though advection has very limited roles to play in waterlogged areas with diminishing trend of groundwater velocity. Total salt in the soil of the selected locations of the Dharoi command is given in Table 2, before and after the command area development. It is arguable that increased salt contents not only make the water contaminated, but also intensify clogging of the pores.Therefore in the irrigation commands, transport mechanism does not merely use the flow vectors but also interact to influence the flow vectors. In SWIFT such transport equation is formulated as equation (7) in transient condition, for the steady state right hand side 
would become zero;

$-\nabla(\rho C u)+\nabla(\rho E C \nabla C)+C I q-C q+R C^{\prime}=\delta(\varphi \rho C \delta t)(7)$

where $R c^{\prime}=$ salt dissolution, $C=$ concentration, $E c=$ tensorial term including dispersion

and molecular diffusion, $C I$ is the concentration of injected water and $q=$ source/sink.

P.K. Majumdar The salt dissolution mechanism appears in the fluid flow equation (3) through the source term $R C$ and in the transport, through the source term $R C^{\prime}$ in the equation (7). These quantities are defined by $R c=\varphi$ $\rho k c f c(1-C c)(8)$ and

$R c^{\prime}=C c R c(1+C c)(9)$

where $C c$ is coefficient for increase in fluid density with increasing concentration given

by $C c=(\rho I-\rho N) \rho o(10)$

Here $\rho N$ is fluid density at reference temperature and pressure and zero concentration, $\rho I$ is fluid density at reference temperature and pressure and unit concentration and $\rho O$ fluid density for the initial conditions. To characterise the dissolution process, two parameters were used, namely, a rate solubility product constant $k C$ and a mass fraction $f C$ of solubleto total solid mass.

P Majumdar et al. (1997) applied SWIFT in the parts of Malaprabha Command area in southern India, concluding concentration improvements through conjunctive use of surface and groundwater. Now that conjunctive use is frequently associated with raw water use, it should be clear that planning decisions for conjunctive and raw water use have separate but multiple goals to achieve, not just sustain able crop water requirement. A base case model from the calibrated of Khediya (2012) is developed to find out parameter intriguing interactive effects of salinity and water-logging. Sensitivity of conjunctive and raw water use has also been examined on the same model.

\section{f.Calibrated perched aquifer model}

Khediya (2012) developed the calibrated perched aquifer model with finite difference grid as shown in Figure 4. An aquifer area of $50 \mathrm{~km} \times 50 \mathrm{~km}$ was discretised to have 20 rows and that many columns and single grid size of $2.5 \mathrm{~km} \times 2.5 \mathrm{~km}$. Two layers having thicknesses of $3 \mathrm{~m}$ and $18 \mathrm{~m}$ respectively from top were provided with inactive blocks surrounding the perched aquifer boundaries and had no aquifer influence blocks. SWIFT model input variables for topography, Sin X and Sin Y were 5.71E-4 and -1.03E-3 respectively for slopes in $\mathrm{X}$ and $\mathrm{Y}$ directions. In local scale ground slope varied as shown in Table 4. Slope changed between grid blocks 15-18 column-wise and 4-7 row-wise, where topography was flatter as compared to the surrounding blocks and falling under the water logged area. The boundary conditions implied were that of a pot aquifer model, where interaction between the reservoir and the aquifer was influenced by an estimated value of 625 $\mathrm{cum} / \mathrm{pa}$ of pressure change. Surface recharge to the model domain was kept as $1.0 \mathrm{E}-9 \mathrm{~m} / \mathrm{sec}$. Recharge production rates from each of the 64 wells were provided as $10,000 \mathrm{~m} / \mathrm{sec}$. The estimated well index and bottom hole pressure values of $5.5737 \mathrm{sqm} / \mathrm{sec}$ and 14,709.5 pa were also provided for these runs.

\section{g.Base case model for salinity}

Using SWIFT, the base case model for salinity analyses is developed. The region is much smaller and size of the grid blocks governed by the Peclet number. Single block taken out from the calibrated flow model domain of Khediya (2012) is celled with 20 grids in both $\mathrm{X}$ and $\mathrm{Y}$ directions, resulting in to single block dimensions of $125 \mathrm{~m}$ in each. Vertical heterogeneity is kept similar to that of the flow model, whereas individual layers are kept horizontally homogeneous having properties of the chosen flow model block. Based upon the Peclet number and standard ratio between longitudinal and transverse dispersivities, same are considered as 125 $\mathrm{m}$ and $12.5 \mathrm{~m}$ respectively with diffusivity value as $0.000093 \mathrm{~m} 2 \mathrm{sec}$. Initial concentration of clean water is considered as zero at its density $1,000 \mathrm{~kg} / \mathrm{m} 3$ and allowed to reach ultimate fluoride concentration of $2.0 \mathrm{ppm}$ at some locations with density of contaminated water as $1,160 \mathrm{~kg} / \mathrm{m} 3$. Steady state boundary conditions were imposed on all the 152 boundary blocks, extrapolated from the flow model for pressure and from well observation data in case of concentration. Surface recharge options were same as that of the flow model with recharge value modified to $0.0001 \mathrm{~m} / \mathrm{sec}$ in order to make it equal to the well production. Source/sink effect is provided through wells in all the 400 blocks with computed well index as $5.4737 \mathrm{~m} 2 / \mathrm{sec}$, production rate as $0.0001 \mathrm{~m} 3 / \mathrm{sec}$ and fluoride concentration of drafted water as $1.95 \mathrm{ppm}$. By creating a system having recharge equals to production, a base case is developed on which it is easier to address if-what trials both in steady state as well as in transient runs. Rate specification option through mobility and pressure drop between the blocks was selected so as to avoid the influence of bottom hole pressure value. Salt dissolution parameter was considered as $0.001 / \mathrm{sec}$. A base case Fluoride concentration distribution computed in steady state condition is presented in Figure 6. 
Table 3 Local scale Topography modification for SWIFTII

\begin{tabular}{|c|c|c|c|c|c|c|c|c|c|c|}
\hline \multirow{3}{*}{$\begin{array}{l}\text { Dissolution } \\
\text { coefficient } \\
\text { in per } \\
\text { second }\end{array}$} & \multicolumn{10}{|c|}{$\begin{array}{l}\text { Computed Pressure at Datum in the unit 'Pascal' multiplied by } 10^{5} \text { and } \\
\text { concentration in mass fraction for the specified grid blocks }\end{array}$} \\
\hline & \multicolumn{2}{|c|}{$(5,7)$} & \multicolumn{2}{|c|}{$(5,15)$} & \multicolumn{2}{|c|}{$(10,10)$} & \multicolumn{2}{|c|}{$(15,5)$} & \multicolumn{2}{|c|}{$(15,15)$} \\
\hline & $P$ & $C$ & $P$ & $C$ & $P$ & $C$ & $P$ & $C$ & $P$ & $C$ \\
\hline \multirow[t]{2}{*}{.000001} & 0.278 & 0.001 & 0.272 & 0.001 & 0.276 & 0.001 & 0.282 & 0.001 & 0.274 & 0.001 \\
\hline & & 769 & & 751 & & 769 & & 744 & & 771 \\
\hline \multirow[t]{2}{*}{0.00001} & 0.281 & 0.291 & 0.267 & 0.290 & 0.277 & 0.291 & 0.288 & 0.290 & 0.272 & 0.291 \\
\hline & & 88 & & 74 & & 92 & & 76 & & 61 \\
\hline \multirow[t]{2}{*}{0.0001} & 0.296 & 0.689 & 0.271 & 0.688 & 0.289 & 0.689 & 0.308 & 0.688 & 0.282 & 0.689 \\
\hline & & 72 & & 94 & & 76 & & 97 & & 39 \\
\hline \multirow[t]{2}{*}{0.001} & 0.438 & 0.854 & 0.407 & 0.854 & 0.429 & 0.855 & 0.453 & 0.854 & 0.420 & 0.854 \\
\hline & & 49 & & 57 & & 49 & & 57 & & 47 \\
\hline \multirow[t]{2}{*}{0.01} & 1.859 & 0.871 & 1.796 & 0.871 & 1.840 & 0.871 & 1.892 & 0.871 & 1.822 & 0.871 \\
\hline & & 28 & & 40 & & 28 & & 39 & & 29 \\
\hline
\end{tabular}

Note: Notation: $P$ for pressure head and $C$ for concentration.

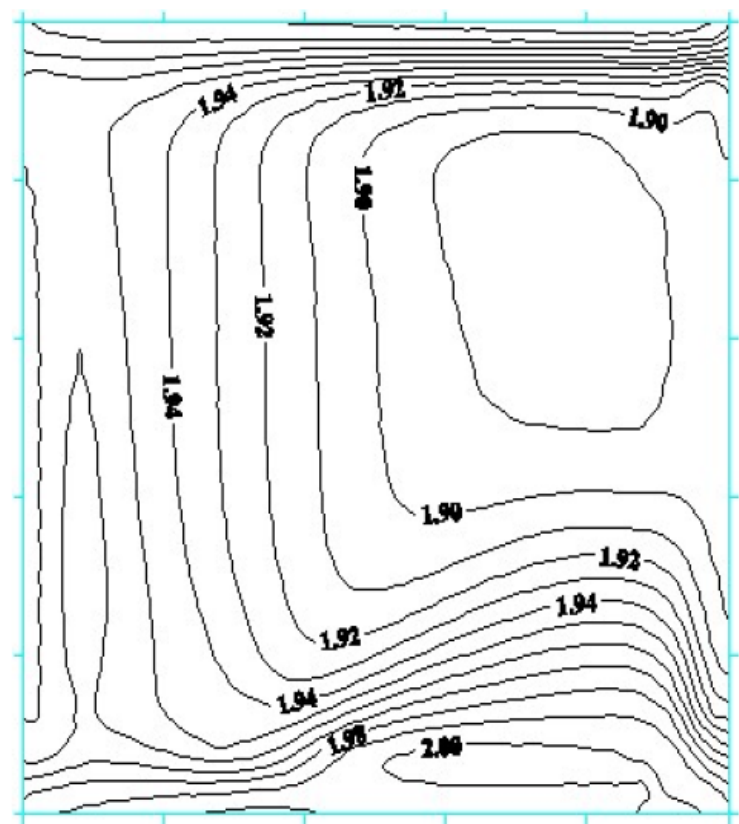

Figure 6 Computed-base case fluoride concentration $(\mathrm{mg} / \mathrm{l})$ plumes in the salinity model

Table 4 Comparision of the Pressure and Concentration computed under varied dissolution constant.

\begin{tabular}{|c|c|c|c|c|c|c|c|c|c|c|}
\hline \multirow{3}{*}{$\begin{array}{l}\text { Dissoliutron } \\
\text { coeficient } \\
\text { in por } \\
\text { second }\end{array}$} & \multicolumn{10}{|c|}{$\begin{array}{c}\text { Computed Pressime at Dation } m \text { the unit "Pascal" muitiplied by I0 } 0^{3} \text { and } \\
\text { concentration in mass fraction for the specined grtd blocks }\end{array}$} \\
\hline & \multicolumn{2}{|c|}{$(5,7)$} & \multicolumn{2}{|c|}{$(5,15)$} & \multicolumn{2}{|c|}{$(10,10)$} & \multicolumn{2}{|c|}{$(25,5)$} & \multicolumn{2}{|c|}{$(15,15)$} \\
\hline & $P$ & C & $P$ & $c$ & $P$ & $C$ & $P$ & $C$ & $P$ & $C$ \\
\hline \multirow[t]{2}{*}{000001} & 0.278 & 0.001 & 0.272 & 0.001 & 0.276 & 0.001 & 0.282 & 0001 & 0.274 & 0001 \\
\hline & & 769 & & 751 & & 769 & & 744 & & 771 \\
\hline \multirow[t]{2}{*}{0.00001} & 0.281 & 0.291 & 0.267 & 0.290 & 0.277 & 0.291 & 0.288 & 0.290 & 0.272 & 0.291 \\
\hline & & 88 & & 74 & & 92 & & 76 & & 61 \\
\hline \multirow[t]{2}{*}{0.0001} & 0296 & 0.689 & 0.271 & 0.688 & 0.289 & 0.689 & 0.308 & 0.688 & 0282 & 0.689 \\
\hline & & 72 & & 94 & & 76 & & 97 & & 39 \\
\hline \multirow[t]{2}{*}{0.001} & 0.438 & 0.854 & 0.407 & 0.854 & 0.429 & 0.855 & 0.453 & 0854 & 0.420 & 0.85 \\
\hline & & 49 & & 57 & & 49 & & 57 & & $47=$ \\
\hline \multirow[t]{2}{*}{0.01} & 1.859 & 0.871 & 1.796 & 0.871 & 1.840 & 0.871 & 1.892 & 0.871 & 1.822 & 0.87 \\
\hline & & 28 & & 40 & & 28 & & 39 & & 29 \\
\hline
\end{tabular}

Note: Notation: $\mathrm{P}$ for pressure head and $\mathrm{C}$ for concentration. 


\section{Results And Discussion}

Effects of dissolution constant on the pressure and concentration solutions at the selected locations of the micro-scale base case salinity model are shown in Table 9. Constants are arbitrarily chosen ranges irrespective of any definite chemical species. It could also be estimated for solubility of specific contaminants and incorporated in the model. Again steady state runs indicated more clarity in the observation; where as transient runs executed lesser sensitivity may be due to uncertainty in the transport parameters and boundary conditions and therefore not presented in the paper. However in both the runs it is indicated that with increase in the dissolution constant, pressure and concentration mass fraction of water increases. Therefore excessive use of fertilizers and nutrients could also cause the water-logging and salinity problem. Conjunctive use of surface and groundwater has been a regular remedy for water logging and salinity problems. Prospects for the same have been examined on the base case salinity model. The operations those executed on the model were first, injecting various proportions of surface water for irrigation having contaminant mass fraction as zero, and secondly injecting a fixed quantity of raw water having varied mass fraction. It is worth mentioning here that base case scenario was developed with both recharge and well production rate as $0.0001 \mathrm{~m} / \mathrm{sec}$ in all 400 grid blocks. It is estimated that on an average irrigation water is applied at a rate $10 \mathrm{~mm} /$ day. Conjunctive use trial runs are executed with 2.5, 5.0 and $7.5 \mathrm{~mm} / \mathrm{day}$. Dissolution constant in these runs are considered as 0.0001 per second. Results of the model runs are abstracted in Table 10. More surface water use reduces the concentration but increases the pressure head. Similar attributes could be seen with drafting out contaminated groundwater as well; however its untreated reuse for the irrigation may increase the contaminant concentration of the groundwater. Results in Table 10 indicate increase in the mass fraction of contaminants with the deteriorating quality of raw water. Therefore raw water use in the irrigation command may have to be seen in respect of the quality of groundwater, not merely in the perspective of quality required for irrigation application.

\section{Conclusions}

The present paper has examined and developed an altered realisation that, water-loggingcould be defined as regional groundwater flow approaching a well storage condition locally with clogging of pores due to abrupt velocity reductions governed by a topography, exhibiting a steeper slope followed by a flatter one, all of a sudden. Therefore appropriate modelling approach dealing with such problems requires treating both regional as well as localised flow domains. Consequently, single software. capabilities were not found sufficient to solve complex concepts of water-logging and salinity. Hence present study was carried out, using multiple software application for groundwater modelling. Parameters such as; aquifer and well skin hydraulic conductivities, topography and solubility have been introduced for the first time in a groundwater modelling study of a waterlogged region. With these, the trials for conjunctive use and raw water application have become more meaningful. Such parameters analyse the problem of water logging and salinity more effectively and remedial measures would be effective on field. Significant conceptual improvement is aimed in the paper and could be more fruitful, if carried out at the planning stages of the command area development. Such modelling studies could ensure better preservation of irrigation command areas in future.

\section{References}

[1]. Abdulaziz, A.M. (2010) 'A mathematical modelling approach for irrigation water management under water shortage and salinity conditions: the Wave_Ms model', Proc. Fourteen International Water Technology Conference, IWTC 14, Cairo, Egypt.

[2]. Ahmed, I. and Umar, R. (2009) 'Groundwater flow modelling of Yamuna-Krishni interstream, a part of central Ganga Plain Uttar Pradesh', J Earth Syst. Sci., Vol. 118, No. 5, pp.507-523.

[3]. Ajdary, K., Singh, D.K., Singh, A.K. and Khanna, M. (2005) 'Simulation of water distribution under drip irrigation using hydrus2D', Proc. XII World Water Congress, Water for Sustainable Development - Towards Innovative Solutions, New Delhi, India.

[4]. Arora, A.N. and Goyal, R. (2012) 'Groundwater model of waterlogged area of Indira Gandhi Nahar Pariyojna, Stage I', ISH Journal of Hydraulic Engineering, Vol. 18, No. 1, pp.45-53. Banar, H. (2011) Modelling of Irrigation Return Flow in Unconfined Aquifer of Dharoi Commanin Mehsana District Of Gujarat, India, Unpublished Postgraduate Dissertation, Gujarat Technological University, India.

[5]. Bastiaanssen, W.G.M., Allen, R.G., Droogers, P., D’Urso, G. and Steduto, P. (2007) 'Twenty-five years modeling irrigated and drained soils: state of the art', Agricultural Water Management, Vol. 92, No. 3, pp.111-125.

[6]. Biggs, A.J.W., Power, R.E. and Brough, D.M. (2003) A Preliminary Assessment of Salinity Risk Modelling in the Queensland Murray-Darling Basin, Department of Natural Resources and Mines, Locked Bag 40, Qld 4151, Coorparoo, DC.

[7]. Bradley, E. and Phadtare, P.N. (1989) 'Paleohydrology affecting recharge to over-exploited semi-confined aquifers in the Mehsana area, Gujarat State, India', Jr of Hydrol., Vol. 108, pp.309-322.

[8]. Burkhalter, J.P. and Gates, T.K. (2005) 'Agroecological impacts from salinization and waterlogging in an irrigated river valley', $J$. Irrig. Drain. Eng., Vol. 131, No. 2, pp.197-209.

[9]. Burkhalter, J.P. and Gates, T.K. (2006) 'Evaluating regional solutions to salinization and waterlogging in an irrigated river valley', J. Irrig. Drain. Eng., Vol. 132, No. 1, pp.21-30.

[10]. Chowdary, V.M., Rao, N.H. and Sarma, P.B.S. (2005) 'Decision support framework for assessment of non-point-source pollution of groundwater in large irrigation projects', Agric. Water Manage., Vol. 75, No. 3, pp.194-225.

[11]. Crowe, A.S. and Mutch, J.P. (1994) 'An expert system approach for assessing the potential for pesticide contamination of groundwater', Groundwater, Vol. 32, No. 3, pp.487-498. Food and Agriculture Organization of the United Nations (FAO) (1996) Food Production: The Critical Role of Water, World Food Summit, Rome, Italy. 
[12]. Gates, T.K., Burkhalter, J., Phillip, J., Labadie, J.W., Valliant, J.C. and Broner, I. (2002) 'Monitoring and modeling flow and salt transport in a salinity threatened irrigated valley', J. Irrig. Drain. Eng., Vol. 128, No. 2, pp.87-99.

[13]. Goel, M.K., Jain, S.K. and Chaube, U.C. (2005) 'A GIS based model for integrated water resources Management in an irrigation system', Proc. XII World Water Congress, Water for Sustainable Development - Towards Innovative Solutions, New Delhi, India.

[14]. Goncalves, J.M., Pereira, L.S., Fang, S.X. and Dong, B. (2007) 'Modelling and multicriteria analysis of water saving scenarios for an irrigation district in the upper Yellow River Basin', Agric. Water Manage., Vol. 94, No. 1, pp.93-108.

[15]. Gupta, S.K., Deshpande, R.D., Agarwal, M. and Raval, B.R. (2005) 'Origin of high fluoride in groundwater in the North Gujarat Cambay Region, India', Hydrogeology Journal, Vol. 13, No. 4, pp.596-605, DOI, doi:10.1007/s10040-004-0389-2.

[16]. Gusyev, M.A. and Haitjema, H.M. (2011) 'Modeling flow in wetlands and underlying aquifers using a discharge potential formulation', Journal of Hydrology, Vol. 408, pp.91-99.

[17]. Houk, E., Frasier, M. and Schuck, E. (2006) 'The agricultural impacts of irrigation induced water-logging and soil salinity in the Arkansas Basin', Agric. Water Manage., Vol. 85, Nos. 1-2, pp.175-183.

[18]. Kaledhonkar, M.J., Sharma, D.R., Tyagi, N.K., Kumar, A. and van der Zee, S.E.A.T.M. (2012) 'Modeling for conjunctive use irrigation planning in sodic groundwater areas', Agric. Water Manage., May, Vol. 107, pp.14-22.

[19]. Kavalannekar, N.B., Sharma, S.C. and Rushton, K.R. (1992) 'Over-expoitation of an alluvial aquifer in Gujarat', India. J. Hydrological Sciences, Vol. 37, No. 4, pp.329-346.

[20]. Kendy, E. and Bredehoeft, J.D. (2006) 'Transient effects of groundwater pumping and surfacewater- irrigation returns on streamflow', J. Water Resour. Res., Vol. 42, No. W08515, doi:10.1029/2005WR004792.

[21]. Khan, S., Rana, T. and Hanjra, M.A. (2008) 'A cross disciplinary framework for linking farms with regional groundwater and salinity management targets', Agric. Water manage., Vol. 95, No. 1, pp.35-47.

[22]. Khan, S., Xevi, E., O’Connell, N., Madden, J.C. and Zhou, F. (2000) A Farm Scale Hydrologic Economic Optimisation Model to Manage Waterlogging and Salinity in Irrigation Areas, CSIRO Land and Water, PMB 3 Griffith, NSW.

[23]. Khediya, T. (2012) Modelling of Fluoride pollution in Dharoi Command in Mehsana, India, Unpublished Postgraduate Dissertation, Gujarat Technological University, India.

[24]. Kumar, P., Gupta, S.K. and Shukla, K.N. (2000) 'Studies on waterlogging and soil salinity in irrigation commands, role of drainage and challenges in 21 st century', Proc. Eighth ICID International Drainage Workshop, New Delhi, India II, pp.387-394.

[25]. Majumdar, P.K. (2013) 'Sustainability of societal water management practices', Int. J. Society Systems Science, Vol. 5, No. 2, pp.113-135.

[26]. Majumdar, P.K., Kumar, S., Singh, V. and Jose, M.K. (2005) 'Characterization of groundwater flow in depleting water table areas in Central Punjab', Proc XII World Water Congress of IWRA, New Delhi, India.

[27]. Majumdar, P.K., Purandara, B.K., Rao, P.R. and Babu, G. (1997) Groundwater Quality Modelling in Nargund Navalgund, CS(AR)30/96-97, National Institute of Hydrology, Roorkee, India publication.

[28]. Majumdar, P.K., Sekhar, M., Sridharan, K. and Mishra, G.C. (2008) 'Numerical simulation of groundwater flow with gradually increasing heterogeneity due to clogging', J Irrig. and Drain. Eng., Vol. 134, No. 3, pp.400-404.

[29]. Ukai right bank canal command using remote sensing and geographic information system', Proc. HYDRO2007, Surat, India. for enhancing water use. 